\title{
Energy analysis of an ultrasound-assisted atmospheric freeze- drying process for food
}

\author{
Merone, D. ${ }^{\text {a,b }}$; Colucci, D. ${ }^{\text {a,b }}$; Fissore, D. ${ }^{\text {b }}$ Sanjuan, N.. ; Carcel, J. A. ${ }^{\text {a,* }}$
}

${ }^{a}$ ASPA Group, Department of Food Technology. Universitat Politècnica de València. Camino Vera s/n, 46022. València, Spain.

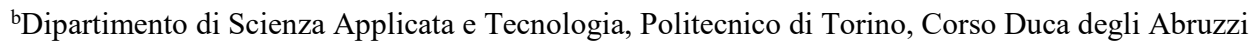
24, 10129 Torino, Italy.

*E-mail of the corresponding author: jcarcel@tal.upv.es

\begin{abstract}
The atmospheric freeze-drying process can be significantly accelerated using power ultrasound. This paper aims to investigate the impact of power ultrasound on the energy consumed by the process. Apple, carrot and eggplant were chosen as representative products with different textures and water content. A mathematical model of the whole plant required to carry out the atmospheric ultrasound-assisted freeze-drying process was developed. Model parameters were tuned according to the results obtained in a pilot-scale unit. Life Cycle Assessment (LCA) was used to gain an insight on the environmental impact of the process. The results showed that the use of ultrasound reduces the total energy consumption of the whole process, while the LCA analysis highlighted the cooling system as the most critical stage for all the impact categories.
\end{abstract}

Keywords: atmospheric freeze-drying; ultrasound; process modeling; LCA. 


\section{Introduction}

During the atmospheric freeze-drying process water is removed from a frozen product thanks to the difference between the water partial pressure in the ice and in the drying chamber [1]. To guarantee this driving force, a stream of dry air is used as carrying agent for moisture [2]. This provides some specific advantages with respect to the traditional batch vacuum freezedrying, among others, a continuous processing and a reduction of total energy consumption [3]. Besides, the advantages of low temperature drying, in terms of product quality, are also obtained in this case [4]. The limiting step of the atmospheric freeze-drying process is the low drying rate that can be achieved, and thus several methods have been proposed to accelerate it. In this sense, power ultrasound appears to be particularly successful to increase drying kinetics [5]-[7], without affecting product quality [8], mainly because of the moderate thermal effect with respect to other techniques, e.g. microwaves.

However, a rigorous investigation on the impact of power ultrasound on the energy consumed by the process is still missing; this paper aims to gain an insight on this issue.

\section{Materials and Methods}

The research included the following steps: products with different porosity were chosen and the kinetics of the ultrasonically assisted dehydration were obtained from literature; the actual energy consumption of a laboratory dryer with ultrasound application was measured and a model of an industrial scale drier was developed. Finally a life cycle assessment (LCA) was carried out to calculate the potential environmental impacts of the process.

\subsection{Raw materials}

Three different products were considered in this study, namely apple (Malus domestica cv. Granny Smith), carrot (Daucus carota L.) and eggplant (Solanum melongena L.), whose experimental drying kinetics have been published elsewhere [5]-[8]. These products are characterized by a very different internal structure, which explains their different porosity ( 0.423 for the eggplant, 0.233 for the apple and 0.031 for the carrot) [9]. From the literature, the moisture effective diffusion coefficients at different drying conditions were obtained:

- air velocity: 1, 2 and $4 \mathrm{~m} \mathrm{~s}^{-1}$;

- air temperature: $-10,0,10$ and $20^{\circ} \mathrm{C}$

- ultrasonic power applied: $0,10.3,20.5 \mathrm{~kW} / \mathrm{m}^{3}$. 


\subsection{Lab-scale dryer}

The experimental drying kinetics of these products were determined in a lab-scale dryer [5] which consists of a cylindrical chamber where food samples are placed. The chamber acts as the ultrasound radiator, which is directly connected to a piezoelectric transducer. The required air flow rate is obtained through a fan. The air at the exit of the chamber is recycled, and the temperature of the air is thus decreased by means of a heat exchanger, using a glycolwater solution $(45 \% \mathrm{v} / \mathrm{v})$ at $-19^{\circ} \mathrm{C}$. The cold air is subsequently heated at the desired drying temperature in contact with an electric resistance. The air stream is then forced to pass through a desiccant material, which is periodically changed and regenerated. The electric energy consumed by the different elements of the systems (fan, ultrasonic generator and heating resistance) was experimentally measured with a power quality analyzer (Fluke 435, Fluke Corporation Holland) at the different drying conditions considered.

\subsection{Industrial-scale dryer}

In order to assess the effect of the operating conditions on the energy consumption of the real freeze drying process, an industrial-scale process was designed and simulated. A sketch of the industrial-scale dryer is shown in Fig. 1.

In the system, the frozen product is placed onto the shelves of the drying chamber. Dry cold air flows continuously, heating the product (as ice sublimation is endothermic) and removing the moisture. The outlet air is then filtered and cooled in such a way that the moisture is partially removed. This system also encompasses a desiccant wheel, which removes the moisture from the air, and a heating system which increases the temperature of the air stream used to regenerate the desiccant material/wheel. Before entering the drying chamber, a heating system is used to bring the process air to the required temperature. Moreover, airhandling systems are used to move both the stream of air to the drying chamber and that used for the regeneration.

The plant was designed to process $100 \mathrm{~kg}$ of fresh product, with a shelf size of $2 \mathrm{~m} \mathrm{x} 1 \mathrm{~m}$ and a shelf-to-shelf distance of $0.1 \mathrm{~m}$.

\subsection{Mathematical modeling}

A mathematical model was used to calculate the energy consumption of the different systems of the lab-scale dryer. Model parameters were tuned based on the results obtained in the labscale unit, thus allowing the use of the model to simulate the whole industrial dehydration process. The air stream was considered to be incompressible, due to the low pressure drop. The pressure drop in the various pieces of the equipment was calculated according to their 
geometry. A temperature drop of $2{ }^{\circ} \mathrm{C}$ was considered in the drying chamber due to the exchange with the external environment, independently of the operating conditions (as measured experimentally). Regarding the cooling unit, the outlet air temperature was determined modeling the heat exchange in the unit according to its specific geometry. The drying kinetics of the investigated products was modelled according to the data available in the literature [5]-[7].

As to the modelling of the industrial-scale apparatus, the model of the drying chamber was the same reported by Colucci et al. [7], while data about the energy required by the desiccant system were taken from the catalogue of the manufacturer [10]. The energy consumed by the ultrasound system was calculated using the correlation obtained in the lab-scale system, while the pressure drops, and the heat exchanged, were calculated taking into account the specific geometry of the system.

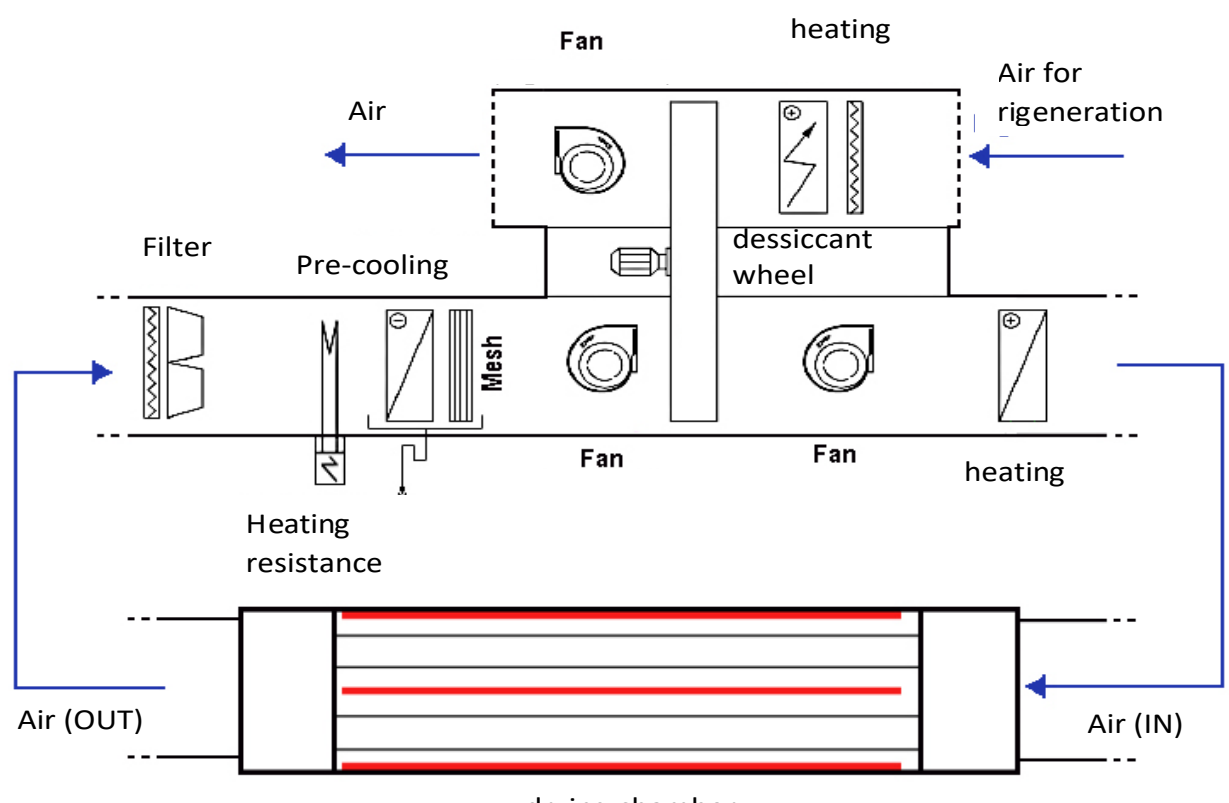

drying chamber

Fig. 1: Sketch of the industrial unit.

\subsection{Life Cycle Assessment}

To calculate the environmental impact of the simulated industrial-scale process of the different products, a Life Cycle Assessment (LCA) [11] was carried out. The functional unit to which all the process inputs and outputs were related was $1 \mathrm{~kg}$ of processed product. Gate 
to gate system boundaries were set. Capital goods manufacturing were not included. Process inventory data were obtained from the mathematical simulation of the industrial plant whereas background data (production of electricity, ethylene glycol, R-404) were obtained from Ecoinvent 3.1 database. ReCiPe 1.08 with a hierarchical approach was used to calculate the environmental impacts.

\section{Results}

In the first part of the study, the values of the actual energy consumption in the different units of the lab-scale dryer were compared to the calculated ones. Thus, the adequacy of the proposed equations used was proved/tested, and the missing parameters that best fit the experimental results were estimated. The fan and resistance efficiencies were calculated, obtaining values of 0.298 and 0.95 respectively. Using these parameters, the error between the measured experimentally energy consumption, and the calculated one ranged from $0.25 \%$ to $6.25 \%$, depending on the operating conditions considered.

The effect of the air velocity on the energy consumed by ultrasonic generation system was negligible regardless of the product. On the contrary, the higher the air temperature and ultrasound intensity applied, the greater the energy consumed by the system (Fig. 2).

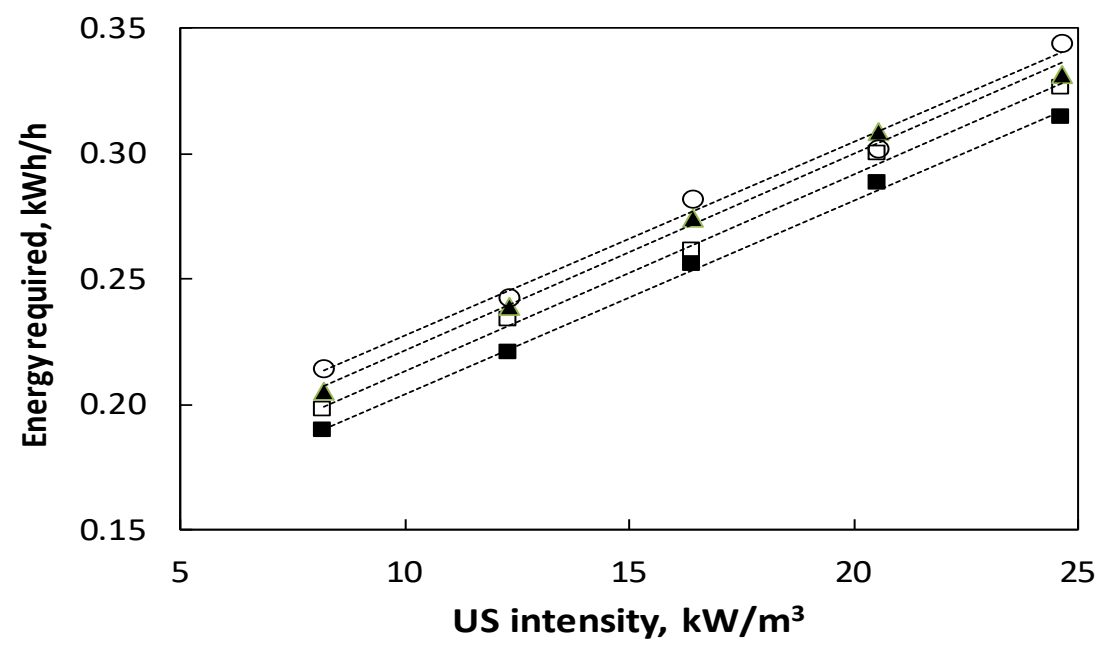

Fig. 2: Influence of the ultrasound (US) intensity and of the operating temperature $\left(\square:-10^{\circ} \mathrm{C}\right.$, $\square$ : $0^{\circ} \mathrm{C}, \triangle: 10^{\circ} \mathrm{C}, \mathrm{o}=20^{\circ} \mathrm{C}$ ) on the energy required by ultrasound generating system. Dotted line shows the linear relationship calculated by Eq. 1.

A linear equation was proposed to relate these parameters: 


$$
P_{U S}=10^{-3} I_{U S}+2 \cdot 10^{-5} T_{\text {air }}^{1.571}
$$

where $P_{U S}$ is the power required by the ultrasound generating system $(\mathrm{kW}), I_{U S}$ is the ultrasound intensity and $T_{\text {air }}$ is the air temperature. This equation was used in the simulation of the industrial scale unit, to calculate the total energy consumed (Fig. 3).

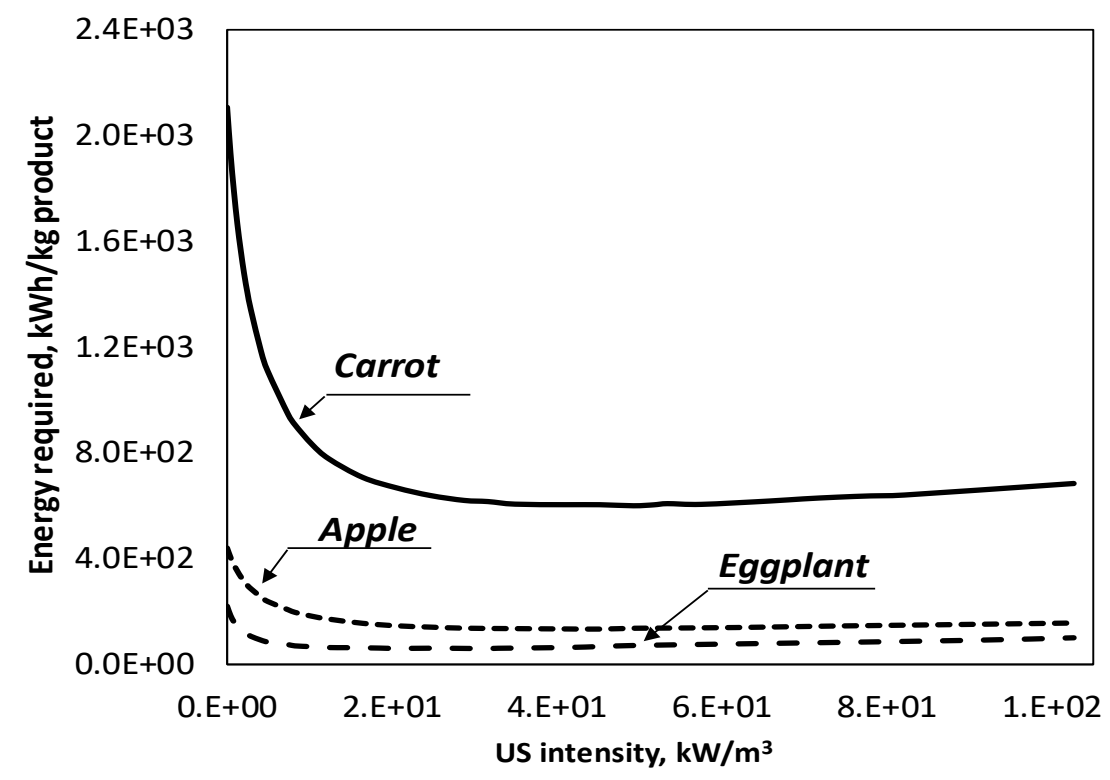

Fig. 3: Influence of the type of product and of the ultrasound (US) intensity on the total energy required by the process.

Relevant differences in the energy consumption were observed for the products considered in the study due to the differences in the water diffusivity, since the higher the water diffusivity the shorter the time needed to dry the product. That means that in the case of ultrasonically assisted drying, although the use of ultrasound increased the energy consumption per hour $\left(\mathrm{kWh} \cdot \mathrm{h}^{-1}\right)$, the total energy consumption of the whole process $(\mathrm{kWh})$ was lower, since the total operation time is reduced. In particular, about $70 \%$ energy reduction was obtained in those drying experiments with an ultrasonic power of $10.3 \mathrm{~kW} / \mathrm{m}^{3}$, regardless of the product processed. An optimal value of ultrasound intensity corresponding to the minimum energy required was observed, as shown in Fig. 2. When ultrasound is applied, the drying time is reduced as well as the total energy consumption. However, when the ultrasound power is above a certain threshold, the increase of the energy consumption per hour of process does not compensate the drying time reduction. 
The LCA results showed that the use of ultrasound allowed all the impact indicators to be reduced compared to a conventional atmospheric freeze-drying process (Fig. 4). Besides, the LCA results highlighted the cooling system as the most critical stage for all the impact categories studied. This is mainly due to the use of ethylene glycol and R-404 in the refrigeration cycle. Nevertheless, when dehydrating low porosity products, the energy consumption of the air dryer increased, and this stage becomes the most critical from an environmental point of view.

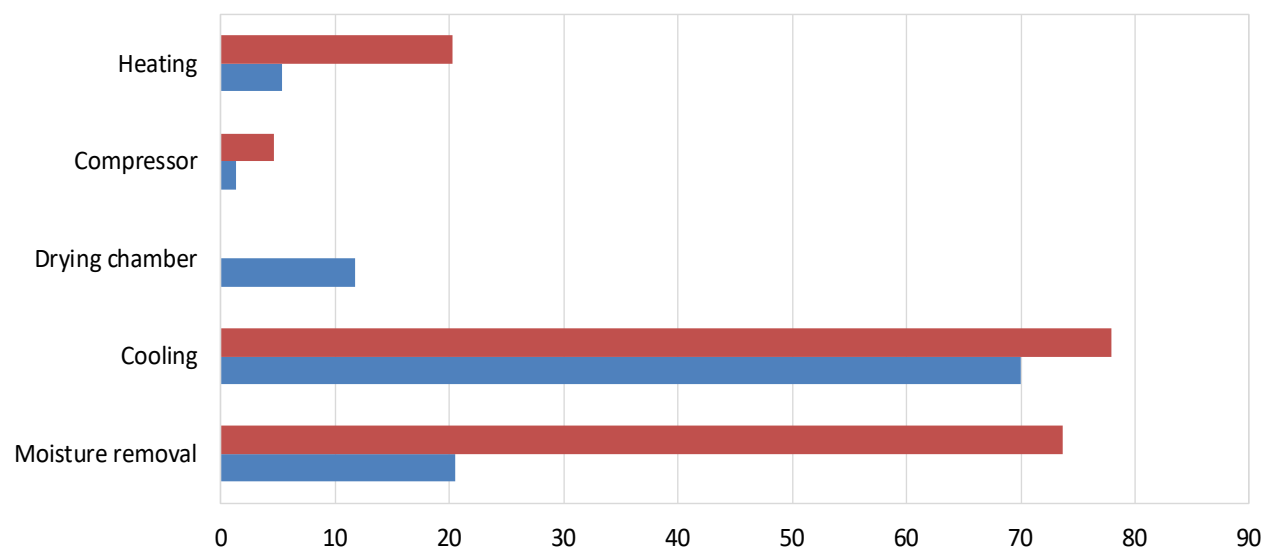

Fig. 4: Climate change impact, as kg-equivalents of $\mathrm{CO}_{2}$, for the atmospheric freeze-drying of $1 \mathrm{~kg}$ of eggplant. Red bar shows data for non-ultrasonic assisted drying and blue bar for ultrasonically assisted freeze drying $(20.5 \mathrm{~kW} / \mathrm{m} 3)$

\section{Conclusions}

The use of power ultrasound in an atmospheric freeze-drying process allows to both speedup the process, and to save energy compared to the conventional process. About $70 \%$ of the total energy required by the process can be saved using ultrasound and the main impact parameters considered in a LCA can be reduced of about 40 to $50 \%$. Considering the values of $\mathrm{kWh}$ per $\mathrm{kg}$ of product processed, the process appears particularly attractive for those high porosity products, whose structure allows a high diffusivity of water vapor in the dried layer to be obtained. 


\section{Acknowledgment}

The authors acknowledge the financial support of INIA-ERDF throughout the project RTA2015-00060-C04-02

\section{References}

[1] Meryman, H. T. Sublimation: Freeze drying without vacuum. Science 1959, 130, 628-629.

[2] Claussen, I.C.; Ustad, T.S.; Strommen, I.; Walde, P.M. Atmospheric freeze dryingA review. Drying Technology 2007, 25, 957-967.

[3] Wolff, E.; Gibert, H. Atmospheric freeze drying, part 1: Design, experimental investigation and energy saving advantages. Drying Technology 1990, 8, 385-404.

[4] Stawczyk, J.; Li, S., Witriwa-Rojchert, D.; Fabisiak, A. Kinetics of atmospheric freeze-drying of apple. Transport in Porous Media 2008 66, 159-172.

[5] Garcia-Perez, J. V.; Carcel, J. A.; Rossello, C.; Riera, E.; Mulet, A. Intensification of low-temperature drying by using ultrasound. Drying Technology 2012 30, 11991208.

[6] Santacatalina, J. V.; Fissore, D.; Cárcel, J. A.; Mulet, A.; Garcia-Perez, J. V. Modelbased investigation into atmospheric freeze drying assisted by power ultrasound. Journal of Food Engineering 2015, 151, 7-15.

[7] Colucci, D.; Fissore, D.; Mulet, A.; Carcel, J. A. On the investigation into the kinetics of the ultrasound assisted atmospheric freeze drying of eggplant. Drying Technology 2017, 35, 1818-1831.

[8] Colucci, D.; Fissore, D.; Rossello, C.; Carcel, J.A. On the effect of ultrasoundassisted atmospheric freeze-drying on the antioxidant properties of eggplant. Food Research International 2018, 106, 580-588.

[9] Ozuna, C.; Gómez, T.; Riera, E.; Cárcel, J.A.; García-Pérez, J.V. Influence of material structure on air-borne ultrasonic application in drying. Ultrasonics Sonochemistry 2014, 21, 1235-1243.

[10] Munters, https://www.munters.com/en/solutions/dehumidification/ (date of last access: April 2018)

[11] McDonough, W.; Braungart, M. Cradle to cradle: remaking the way we make things, North Point Press, New York, USA, 2002. 